\title{
NUMERICAL MODEL OF PLASTIC DESTRUCTION OF THICK STEEL STRUCTURAL ELEMENTS
}

\author{
Jakub Kowalski \\ Janusz Kozak \\ Gdańsk University of Technology, Poland
}

\begin{abstract}
In the shipbuilding industry, the risk of brittle fracture of the structure is limited by using certified materials with specified impact strength, determined by the Charpy method (for a given design temperature) and by supervising the welding processes (technology qualification, production supervision, non-destructive testing). For off-shore constructions, classical shipbuilding requirements may not be sufficient. Therefore, the regulations used in the construction of offshore structures require CTOD tests for steel and welded joints with a thickness greater than $40 \mathrm{~mm}$ in the case of high strength steel and more than $50 \mathrm{~mm}$ in the case of other steels. Classification societies do not accept CTOD test results of samples with a thickness less than the material tested. For this reason, the problem of theoretical modeling of steel structure destruction process is a key issue, because laboratory tests for elements with high thickness (in the order of $100 \mathrm{~mm}$ and more) with a notch are expensive (large samples, difficulties in notching), and often create implementation difficulties due to required high load and range of recorded parameters. The publication will show results and conclusions from numerical modeling of elastic properties for steel typical for offshore applications.
\end{abstract}

Calculations were carried out at the Academic Computer Centre in Gdańsk.

Keywords: impact strength, numerical modeling, steel structural elements

\section{INTRODUCTION}

Off-shore constructions are made of steel sheets with increased strength (with a yield point exceeding $290 \mathrm{MPa}$ ) and high strength (with a yield strength exceeding $400 \mathrm{MPa}$ ) of considerable thickness, often greater than $100 \mathrm{~mm}$. After foundation, the structure works 365 days a year, regardless of the environmental conditions such as the state of the sea or the outside temperature. Triaxial state of stress, resulting from the thickness of used metal sheets, dynamic loads from the external environment (wave and wind) and low temperature of the structure, create favorable conditions for the formation of brittle cracks.
A common way to prevent fracture cracking is to validate construction materials and qualify welding technology. Of the various attempts to determine the properties of the material or welded joint, an impact test, also known as the Charpy test, is performed to determine the fracture toughness. The procedure is standardized, usually performed according to PN-EN ISO 148-1:2017-02 or ASTM E23-12c. The result of the test is to determine the work of breaking the notched sample required for destruction in the temperature appropriate for a given steel category. Depending on the test object (material, welded joint), the number of sample sets, the place of their collection, the orientation and the criteria for approval, the sample are selected. For example, for high-strength ship steel with 
a minimum yield strength $=355 \mathrm{MPa}$, category D (impact test temperature: $-20^{\circ} \mathrm{C}$ ), the minimum required impact strength is $34 \mathrm{~J}$ along the rolling direction and $24 \mathrm{~J}$ across the rolling direction for sheet metal up to $50 \mathrm{~mm}$, and for sheets with thicknesses in the range $70-100 \mathrm{~mm}$, the required impact strength will be as high as $50 \mathrm{~J}$ along the direction of rolling and 34 crosswise [1]

The relationship between the test temperature and the mechanism of destruction for steel is shown by a graph of breaking energy called the fracture curve, Fig. 1, however, the information obtained during the impact test does not show whether the material will break brittle, ductile or mixed at the test temperature.

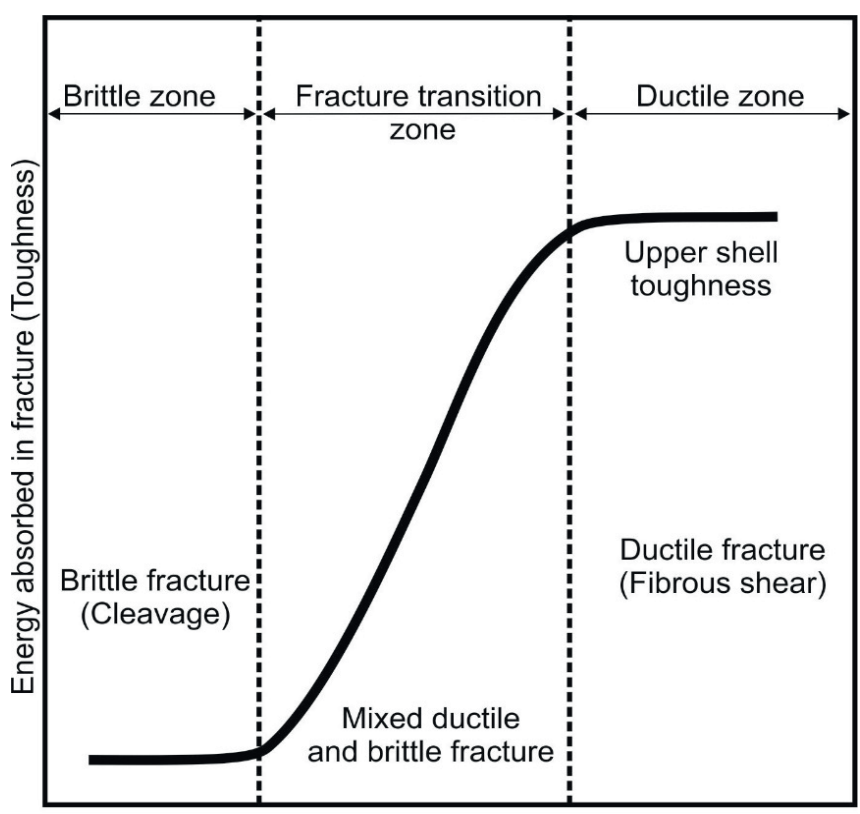

Temperature

Fig. 1. The curve of transition into fragile state [2]

The authors practice [4] shows that in relation to welded joints, it happens that as a result of testing the same material two completely different results are obtained. Broken samples have a different character of the breakthrough and both results are acceptable because the energy needed to destroy them is greater than the minimum required by law. In Fig. it is shown that the Charpy impact test result is purely quantitative.

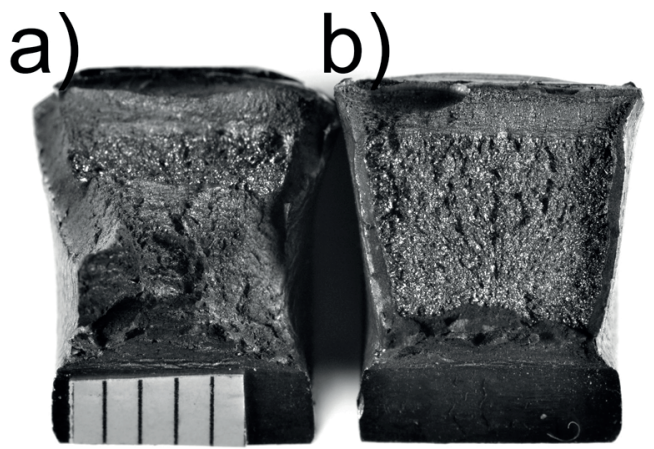

Fig. 2. Charpy impact test result. Both metallographic samples come from one joint zone [4]
The fracture shown in Fig. 2 is ductile, while the fracture of Fig. 2-b is practically completely fragile. Both samples were taken from one zone of the same welded joint $(+5 \mathrm{~mm}$ from the fusion line), the results obtained were $61 \mathrm{~J}$ and $115 \mathrm{~J}$ respectively, both samples met the criterion regarding the minimum required impact strength. The example cited shows that the impact test may in some cases be insufficient to properly determine the ductility of the material.

For the aforementioned reasons, the problem of theoretical modeling of steel structure destruction process is a key issue, because laboratory tests for elements with high thickness (in the order of $100 \mathrm{~mm}$ and more) with a notch are expensive (large samples, difficulties in making notches), and often create difficulties due to the required high load.

\section{MODELING OF MATERIAL BEHAVIOR IN THE PROCESS OF DUCTILE DESTRUCTION OF THICK STEEL STRUCTURAL ELEMENTS}

In order to obtain a correct model of the destruction course in the area of large key deformations, a mechanism or sequence of mechanisms of material particle behavior at the micro level is defined, and further parameters describing these mechanisms in a correct manner are defined. On such a level of perception of metal properties, it is assumed that the mechanism of destruction consists in the growth and merging of microscopic voids that appear at the phase boundary. Early studies on the growth of a single emptiness in the infinite ductile solid [4] have shown that the rate of growth increases significantly when the value of the hydrostatic pressure increases. Subsequent works [5] conducted for the porous, ductile material allowed to add the effect of kinematic strengthening. For a ductile-elastic material subjected to hydrostatic pressure, a level of stress can be achieved where the void growth occurs unstable without further load in the far region. This phenomenon of cavitation instability was described by several authors [6] for spherical, symmetrical load conditions and further analyzed [7].

When defining the numerical model of the material, three phases of behavior can be distinguished: the area of elastic (linear) behavior, plasticization with strengthening and finally degradation of the material up to destruction.

The schematic diagram of such a defined destruction mechanism is presented below (Figure 3). 


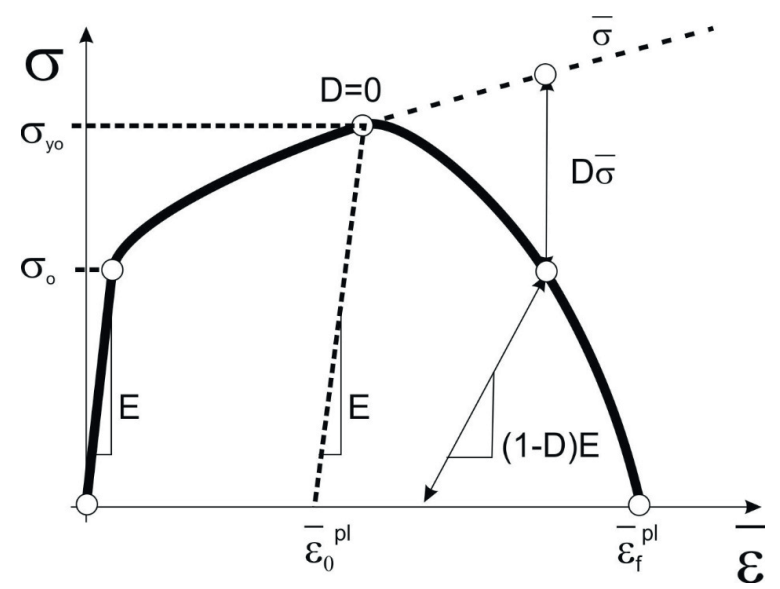

Fig. 3. Diagram of deformation and material degradation process [8]

where:

D - degree of destruction, $(\mathrm{D}=0$ initiation of the degradation process, $\mathrm{D}=1$ - material fully destroyed)

$\varepsilon \quad$ - elongation

$\bar{\varepsilon}_{0}^{p l}$ - ductile deformation reduced for the beginning of the degradation process

$\bar{\varepsilon}_{f}^{p l}$ - plastic deformation reduced at break

E - Young module

$\bar{\sigma} \quad$ - reduced stresses

$\sigma \quad-$ stress

$\sigma_{0}-$ yield point

$\sigma_{\mathrm{y} 0}-$ strength limit

After exceeding the critical value of ductile deformation, the beginning of degradation occurs - depending on the mechanism of destruction by creating the previously mentioned voids or shearing (Fig. 4).

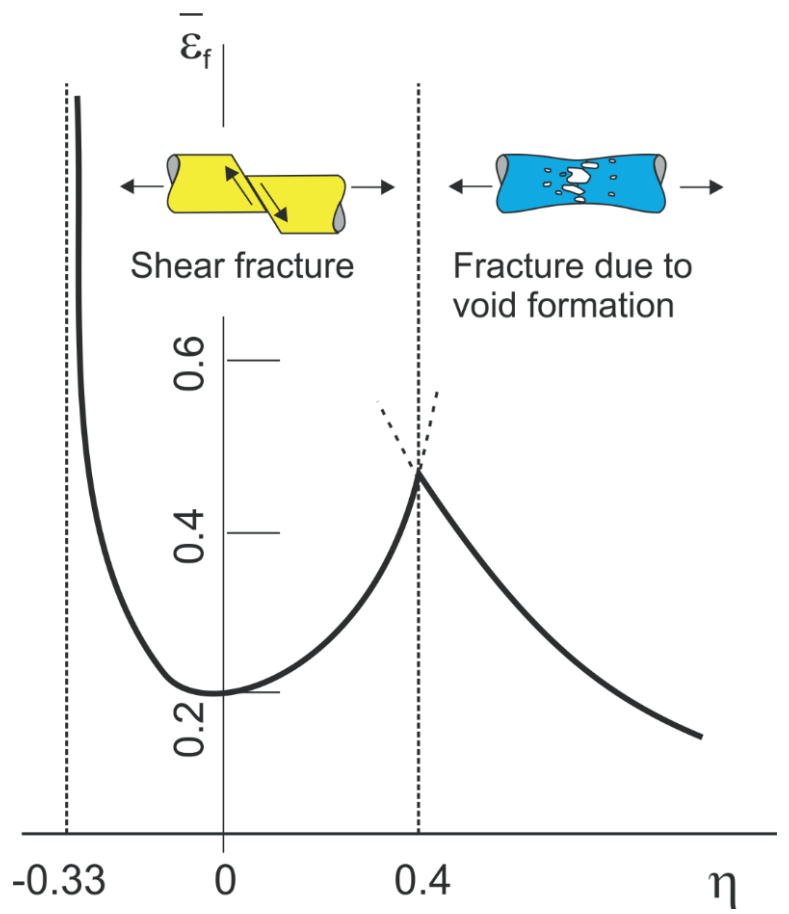

Fig. 4. Change of the destruction mechanism model [9]
The process of void formation is influenced by such state parameters as: stress triaxiality - denoted as $\eta$, defined as the ratio of reduced stress to the pressure inside the element - formula 2; reduced ductile deformation and strain rate. In turn, the mechanism responsible for shearing is a function of such parameters as: shear stress ratio (dependent on reduced stresses, pressure inside the element, maximum shear stress and the pressure influence parameter $\mathrm{k}_{\mathrm{s}}$ ), reduced ductile deformation and strain rate. Both mechanisms can operate independently of each other or in combination, depending on the material degradation criterion.

As can be seen, the problem of modeling the deformation process and further destruction of the material is associated with the correct determination of the values of stresses occurring in the modeled material. Determining the eigenvalues of stress tensor for the needs of the numerical model is cumbersome. The description of the change in the state of stress in the element of a convenient and useful parameter is $\eta$. This indicator can be used both to describe the plasticizing function as well as to define the criteria of ductile destruction [10].

The applied strain-based model of initiation and further degradation of the material is a function of:

- equivalent ductile deformation, defined as:

$\varepsilon_{e p l}=\frac{\sqrt{2}}{3} \sqrt{\left(\varepsilon_{1 p l}-\varepsilon_{2 p l}\right)^{2}+\left(\varepsilon_{1 p l}-\varepsilon_{3 p l}\right)^{2}+\left(\varepsilon_{3 p l}-\varepsilon_{2 p l}\right)^{2}}$ (1)

where:

$\varepsilon_{\text {epl }}$ - equivalent ductile deformation [-]

$\varepsilon_{1 \mathrm{pl}}-\varepsilon_{3 \mathrm{pl}}-$ main ductile components of strain tensor [-],

- coefficient of triaxiality of stresses:

$$
\eta=\frac{-p}{q}
$$

where:

$\mathrm{p}[\mathrm{MPa}]$ - hydrostatic pressure in the material defined as:

$$
p=-\frac{1}{3}\left(\sigma_{1}+\sigma_{2}+\sigma_{3}\right)
$$

$\mathrm{q}[\mathrm{MPa}]$ - reduced stresses, i.e.:

$q=\frac{1}{\sqrt{2}} \sqrt{\left(\sigma_{1}-\sigma_{2}\right)^{2}+\left(\sigma_{2}-\sigma_{3}\right)^{2}+\left(\sigma_{3}-\sigma_{1}\right)^{2}}$

where:

$\sigma_{1}-\sigma_{3}[\mathrm{MPa}]-$ main stress

- deformation speed.

The „D” parameter shown in Fig. 3 is called the damage evolution coefficient, which takes values from 0 to 1 . The course of change of this parameter as the destruction process progresses depends on the properties of the material being modeled. 
In numerical models a linear, exponential and tabular description is used.

\section{DEFINING THE MATERIAL MODEL, DETERMINING MATERIAL CONSTANTS AND CALIBRATING CALCULATIONS}

In order to determine the parameters for the material model, a tensile test was conducted for typical steel for the ship's hull structure with a minimum yield point of $235 \mathrm{MPa}$ and category A. The sheet from which the sample was taken was $37 \mathrm{~mm}$ thick, therefore it was possible to prepare samples for both the tensile tests as well as CTOD - for subsequent verification of numerical tests.

The material characteristics obtained during the tensile test have been normalized to the form used in the numerical model:

$$
\begin{gathered}
\varepsilon_{\text {true }}=\ln (1+\varepsilon) \\
\sigma_{\text {true }}=\sigma(1+\varepsilon)
\end{gathered}
$$

where:

$\sigma[\mathrm{MPa}]$ - engineering stresses obtained during the tensile test (without taking into account the change in the cross-section),

$\varepsilon[-] \quad-$ deformations obtained during the tensile test.

The plastic section from the beginning of plasticity to the limit of strength has been described by entering data in the system $\sigma_{\text {true }}-\varepsilon_{\text {plastic-true }}$, where $\varepsilon_{\text {plastic-true }}$ - plastic component of the real strain defined as:

$$
\varepsilon_{\text {plastic_true }}=\varepsilon_{\text {true }}-\varepsilon_{\text {sp }}=\varepsilon_{\text {true }}-\frac{\sigma_{\text {true }}}{E}
$$

where:

$\varepsilon_{\mathrm{sp}}$ - elastic part of the deformation [-]

$\mathrm{E}$ - Young module [MPa], takes 2,1e5 [MPa] - determined from the actual tensile test,

To describe the behavior of the material beyond the breaking point, a procedure based on the power law equation proposed by J.H. Hollomon [11] has been used. The equations presented here provide sufficiently good results for ductile materials and room temperatures [12].

According to the physics of the phenomenon, two models of material destruction were adopted - by void formation a model characteristic of ductile destruction and by shearing characteristic for the last phase of destruction. Characteristic zones for both mechanisms of destruction are presented in Fig. 5 - referring to Fig. 4.

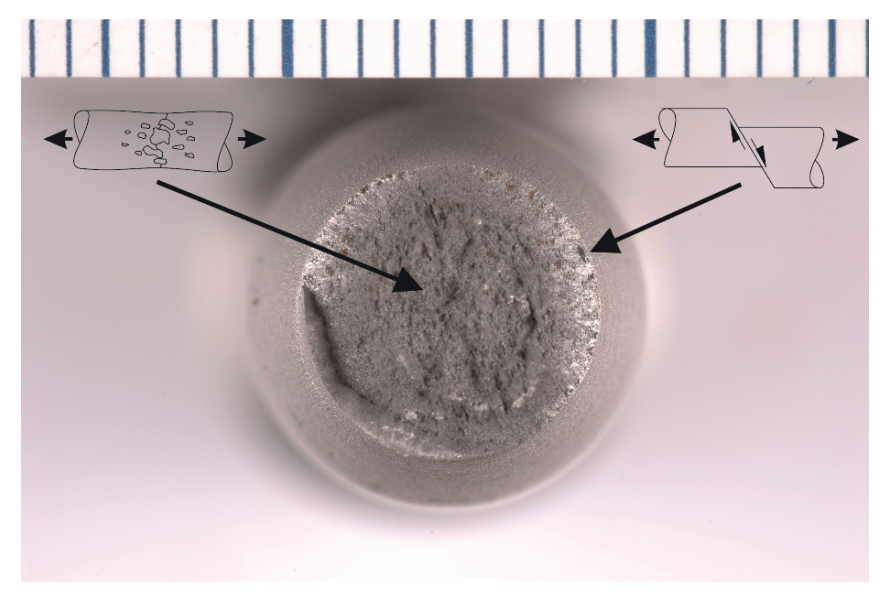

Fig. 5. Determination of zones of changes of damage mechanisms for the tested sample

The material model was calibrated and validated by numerically modeling the tensile test using the developed material model. The plastic properties of the material are defined independently for different areas on the stretching curve. For the linearly elastic area through the Young's E modulus and the Poisson's number determined for the analyzed steel from the tensile test. For the area of flow and ductile strengthening, the true stress - true strain curve was determined, defined by equations (5), (6) and (7).

In the area of ductile flow, after the limit of strength has been exceeded until destruction, a material model was adopted, according to the formula:

$$
\sigma_{\text {eq }}=\mathrm{K} \varepsilon_{\text {eq }}{ }^{n}
$$

where,

$\mathrm{K}, \mathrm{n}$ - material parameters,

$\sigma_{\text {eq }}, \varepsilon_{\text {epl }}-$ stresses reduced according to Huber's hypothesis and reduced ductile deformations (according to formula 1).

As a result of calculations based on the developed destruction model and material data obtained, a numerical model of the stretching process was presented, shown in Fig. 6 against the background of data obtained from a laboratory experiment.

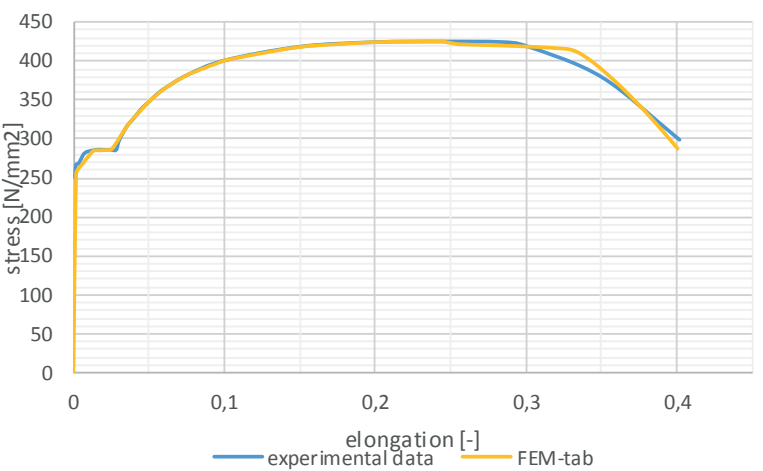

Fig. 6. Comparison of curves obtained by numerical simulation with the curve obtained experimentally 
In addition to checking the response of the MES model to the set loads (initiated by the displacement in time), the form of destruction was controlled, in particular the distribution of the stress triaxiality parameter. Fig. 7 presents the distribution of this parameter on the numerical model. It is convergent with the zones of destruction marked in Figure 5 .

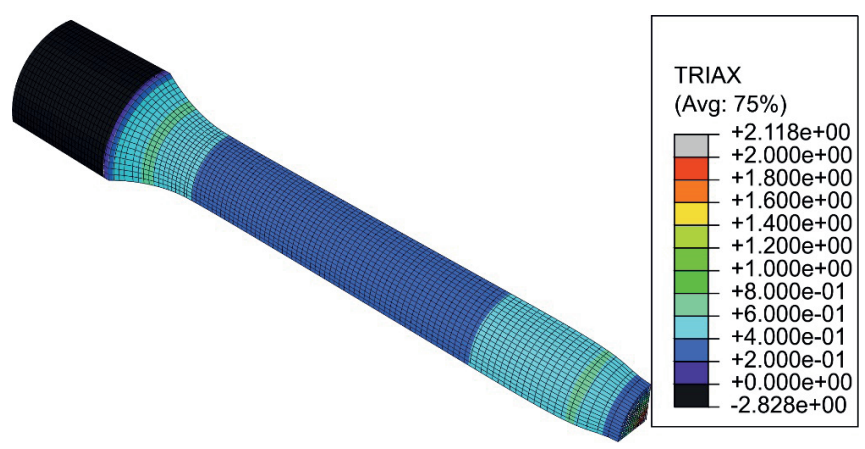

Fig. 7. Distribution of the parameter $\eta$ during the formation of the plastic neck

\section{VALIDATION OF THE MATERIAL MODEL ON A THREE-POINT-FOLDING SAMPLE MODEL}

The developed description of destruction was used to analyze the method of destroying a three-point-fold sample in accordance with the standard [13] for determining the CTOD value. The sample was made of the same material as previously described. It was assumed that the tests will be carried out at ambient temperature, in which the material retains ductile properties, a material model with full plasticity and ductile failure will be used. To create a numerical model it was necessary to reproduce fully ductile behavior and degradation of the material.

The modeling was subjected to a sample geometry as in Fig. 8 , for the parameter values: $\mathrm{W}=60 \mathrm{~mm}, \mathrm{~B}=30 \mathrm{~mm}$, and $/ \mathrm{W}=0.5$.

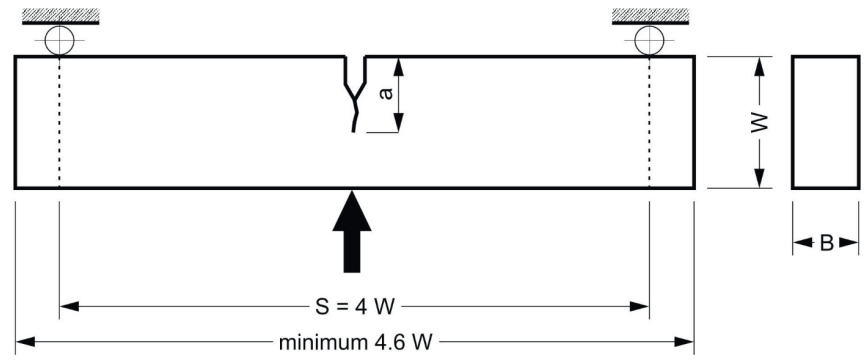

Fig. 8. Geometry of the sample analyzed

For the numerical modeling of the destruction process of a three-point folding sample, due to the two axes of symmetry, a quarter samples and the corresponding supports were modeled. The FEM model is shown in Fig. 9a. A simplification has been used that there is no friction between the supports and the sample. The material model described above was used, including both mechanisms of destruction described. Explicit simulation in the time domain was carried out using the explicit method. Fig. $9 \mathrm{~b}$ presents the distribution of reduced stresses according to the Huber hypothesis, around the crack at the moment of reaching the maximum force (see Fig. 11).

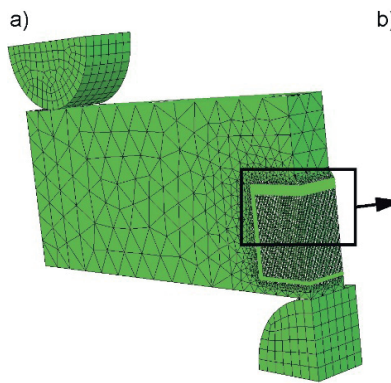

b)

Fig. 9. Numerical model of three-point folding before destruction (a) Distribution of stresses reduced around the crack for the moment of reaching the maximum force value (b)

The sample with the same geometry and material data was subjected to destructive testing through three-point folding - according to the standard [13] - as shown schematically in Fig. 8. The sample in the station during the tests is shown in Fig. 10

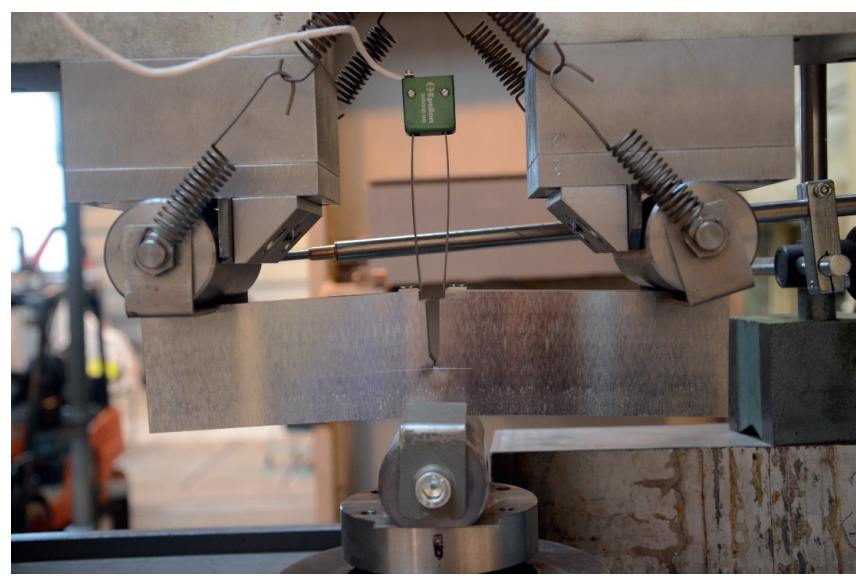

Fig. 10. Real sample during laboratory tests

Figure 10 summarizes the results obtained by FEM simulation and experimental research. As can be seen, satisfactory quantitative convergence was obtained. From the graph it is clearly visible that the numerical model shows clearly higher ductility than it actually is. This is due to the specificity of calibration, in particular from material properties describing the degradation of the metal by shearing. 


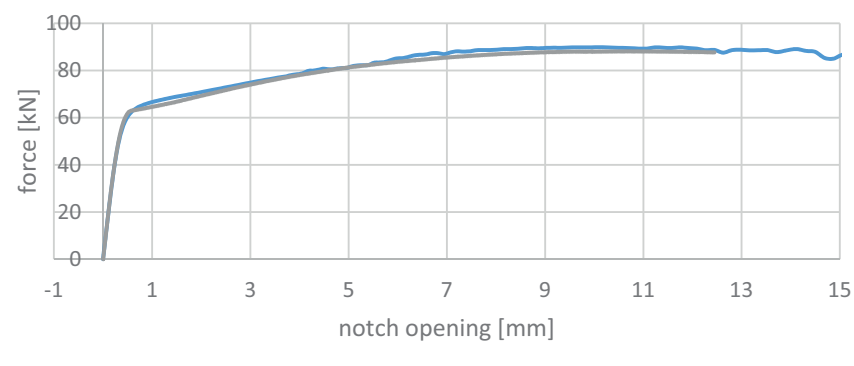

MES W60 a0/W $=0.5 \longrightarrow$ LAB W60 a0/W $=0.50$

Fig. 11. Comparison of the results of numerical analysis and laboratory tests: $W$ and $a_{0}$ values as in Fig. 8

Fig. 12 presents a qualitative summary of the results of the numerical solution and laboratory tests. One can see a very good compatibility of the deformed map of the area near the notch bottom for both solutions.

a)

b)

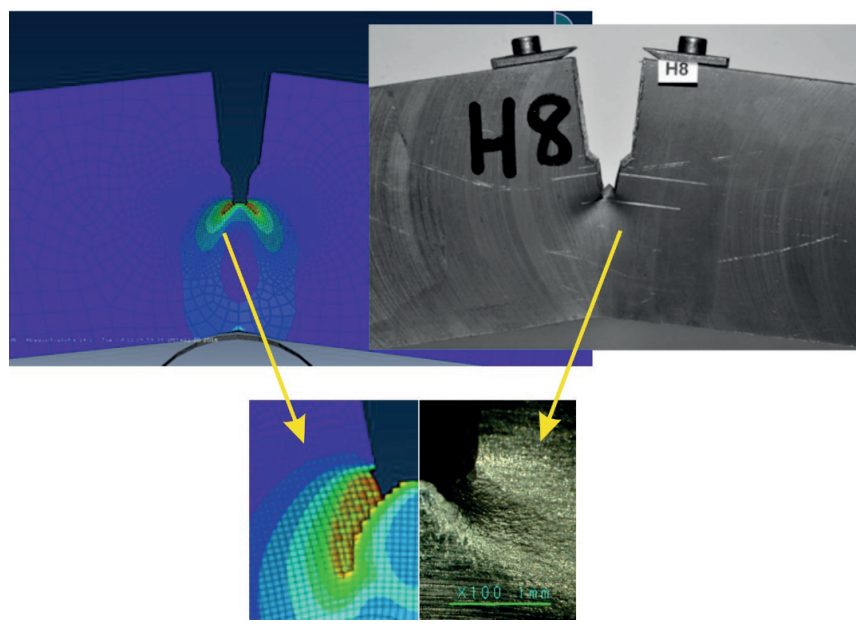

Fig. 12. Comparison of the destruction image: a) from the numerical solution, b) from laboratory tests

\section{SUMMARY AND CONCLUSIONS}

Modeling of elastic-ductile properties of steel for the needs of numerical analysis is a complicated problem and often ambiguously described in the literature.

Modeling the full range of deformation (until the destruction) of a steel element, requires the ability to divide this range into phases that differ in the mechanism of deformation (and destruction), the correct definition of criteria for changing the mechanism and parameters describing it.

For correct mapping of material behavior for the area of ductile flow and reinforcement, it is necessary to determine parameters describing this behavior based on material tests. Because this phase of the process describes exponential functions, the obtained result is very sensitive to small changes in describing parameters, so the process of model calibration should be carried out with special care and, if possible, should be laboratory-verified.

The results of numerical calculations shown show a great potential of the proposed methodology. However, if possible, laboratory verification should be carried out, especially for elements of considerable thickness, due to the complex state of stress in the area of destruction.

\section{LITERATURE}

1. Polski Rejestr Statków, Przepisy Klasyfikacji I Budowy Statków Morskich, Część, IX Materiały i spawanie,, Gdańsk: Polski Rejestr Statków, 2017.

2. Lloyd's Register of Shipping,, Rules for the Manufacture, Testing and Certification of Materials,, London: Lloyd's Register of Shipping, 2015., 2015.

3. J. Kowalski, L. Nadolny and A. Wołoszyn, „Test Report No WOiO/II/105/2013,” Politechnika Gdańska, Gdańsk, 2013.

4. J. R. Rice and D. M. Tracey, „On the ductile enlargement of voids in triaxial stress fields," in J. Mech. Phys. Solids, 17, 1969.

5. A. L. Gurson, „Porous rigid-plastic materials containing rigid inclusions- Yield function, plastic potential, and void nucleation," in Taplin, D. M. R. (Ed.), Proc. Int. Conf Fracture Vol. 2A, , 1977.

6. Y. Huang, J. W. Hutchinson and V. Tvergaard, „Cavitation instabilities in elastic-plastic solids',", in J. Me\& Phys. Solids, 39 , 1991.

7. V. Tvergaard, „Mecanical Modelling of Brittle Fracture”, Meccanica 26: 11-16, Kluwer Academic Publishers. Printed in the Netherlands, 1991.

8. „Abaqus, manual”.

9. W. T. Bao Y., „A Comparative Study on Various Ductile Crack Formation Criteria," in Transactions of the ASME, Vol. 126,, 2004.

10. S. Kut, „State of Stress Indentification in Numerical Modelling of 3D Issues (in Polish)," in Archives of Metallurgy and Materials, Volume 54 Issue 3, 2009.

11. J. Hollomon, „Tensile Deformation,” Trans. AIME, p. 268, 1945. 
12. A. NEIMITZ, J. GAŁKIEWICZ and I. DZIOBA, „KALIBRACJA ZWIĄZKÓW KONSTYTUTYWNYCH PRZY DUŻYCHODKSZTAŁCENIACH PLASTYCZNYCH I DUŻYCH WSPÓŁCZYNNIKACH TRÓJOSIOWOŚCI," in Zestawienie pełnych tekstów referatów XVI KRAJOWEJ KONFERENCJI MECHANIKI PĘKANIA, Pułtusk, 2017.

13. British Standard, BS 7448-1:1991 - Fracture mechanics toughness tests. Method for determination of KIc, critical CTOD and critical J values of metallic materials, Londyn: BSI, 1991.

\section{CONTACT WITH THE AUTHORS}

Jakub Kowalski

e-mail: jakub.kowalski@pg.edu.pl

Janusz Kozak

e-mail:kozak@pg.gda.pl

Gdansk University of Technology

Faculty of Ocean Engineering and Ship Technology

Narutowicza $11 / 12$

80-233 Gdansk

Poland 